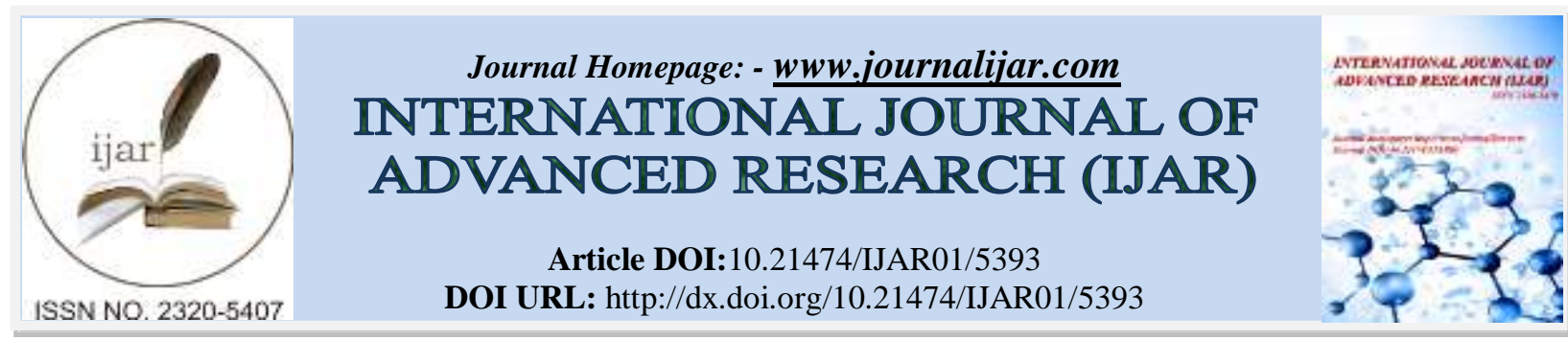

RESEARCH ARTICLE

\title{
ANALYSIS OF THE EPICUTICULAR WAX COMPOSITION OF JASMINUM EMPLOYING SEM-EDX
}

\author{
${ }^{*}$ Regy Yohannan ${ }^{1}$ and Devipriya $\mathrm{V}^{2}$. \\ 1. Department of Botany, Sree Narayana College, Kollam, Kerala, India. \\ 2. Department of Botany, Sree Narayana College, Chempazhanthy, Kerala, India.
}

\section{Manuscript Info}

Manuscript History

Received: 10 July 2017

Final Accepted: 12 August 2017

Published: September 2017

Key words:-

Jasminum auriculatum, Jasminum multiflorum, EDX.

\section{Abstract}

The micromorphology and elemental composition of epicuticular waxes were studied from the foliar upper epidermis of two species viz. Jasminum auriculatum Vahl. and Jasminum multiflorum (Burm. f.) Andrews, using Scanning Electron Microscopic-Energy Dispersive Xray Analysis (EDX).The epicuticular wax crystals of $J$. auriculatum were needle-like and broad, often aggregating to form radiating clusters, while those in J. multiflorum were irregular in shape. The wax crystals of $J$. auriculatum comprised mostly of five elements with Calcium, Oxygen and Carbon in sufficiently larger amounts, while the waxes of $J$. multiflorum had seven major components with Silicon and Oxygen in large amounts. Carbon and Calcium were seen in lower quantities here. This variation in crystal composition needs to be further evaluated to assess whether they are species-specific and would be of aid in the systematic evaluation of the genus.

Copy Right, IJAR, 2017, All rights reserved.

\section{Introduction:-}

Epicuticular waxes on foliar surfaces function as the interface between the plant and its environment, assuming a protective role by retarding excessive loss of water. They are also known to cause the 'lotus-effect', by offering the leaf a water repellant surface which reduces the adhesion of contaminants on the leaf surface. The dust particles, spores etc. on the leaf surface are washed away by the water drops rolling off the waxy surface, aiding in surface purification (Barthlott, 1990; Riederer and Schreiber, 1995). These waxes may range from a thin filmy coating on the epidermal surface to crystalline three-dimensional forms of varied sizes and structure. Scanning Electron Microscopic (SEM) studies by Behnke and Barthlott (1983) have revealed that epicuticular wax micromorphology is not influenced by environmental fluctuations and exhibits systematic linkages across superior angiospermic hierarchies, and this led to their utilization as chemotaxonomic markers by Dahlgren and Bremer (1985). Since then, several studies have been made on this aspect of plant morphology on selected plant groups such as the Ranunculiflorae and Magnoliiflorae (Barthlott and Theisen, 1995), Nelumbo (Barthlott et al., 1996) etc.

Jasminum L., the largest and most economically valued genus of the Oleaceae is native to the tropical and warm temperate regions of the Old World (Green, 1969). The genus with approximately 200 species world over, has been subdivided in to five sections viz. Unifoliolata, Alternifolia, Jasminum, Trifoliolata and Primulina (De Candolle, 1844; Green, 2001). However, there is much ambiguity as regards the sectional classification owing to frequent overlapping of the boundaries as well as phenotypic plasticity arising from the extensive reticulation of exomorphological features. This in turn calls for in-depth analysis of the systematics of the group, employing additional markers. Preliminary SEM studies on the foliar surfaces of selected Jasminum species from Kerala by the 
authors for stomatal and trichome characters revealed variation in the epicuticular organization ranging from granular to full-fledged three-dimensional crystalline forms. The earlier literature regarding the systematic implications of epicuticular wax micromorphology and chemical composition prompted us to undertake this study on two species of the genus viz. Jasminum auriculatum Vahl. and Jasminum multiflorum (Burm. f.) Andrews (Figs. 1 and 2), using SEM-Energy Dispersive X-ray Analysis (EDX). The composition of elements in the epicuticular waxes of the foliar surfaces of these two taxa is studied here.

\section{Materials and Methods:-}

J. auriculatum Vahl and J. multiflorum (Burm.f.) Andrews were collected from Kollam district of Kerala state. The plants were identified by referring standard flora and voucher specimens of the two taxa are deposited in the herbarium at Sree Narayana College, Kollam. Energy Dispersive X-ray Analysis (EDX) is a technique for analyzing elements at the microscopic level. For this purpose, Scanning (SEM) or Transmission (TEM) electron microscopes are equipped with an energy dispersive system for quantitative electron probe X-ray microanalysis (Chen et al., 2014). For the present study, small pieces of fresh leaf were taken, washed with distilled water, air dried and coated with gold. SEM-EDX analyses were carried out using JEOL - JSM - 5600LVSEM with EDX system.

\section{Results and Discussion:-}

In the upper foliar epidermis of $J$. auriculatum, the epicuticular wax crystals were needle-like and broad, often aggregating to form radiating clusters (Fig.3). The element composition of these waxes comprised of 36.14 weight $\%$ of Calcium, 35.52 weight $\%$ of Oxygen, 26.37 weight \% of Carbon, 1.19\% weight of Magnesium, and 0.77 weight $\%$ of Potassium (Table 1). However, the epicuticular wax crystals in the upper epidermis of J. multiflorum were irregular in shape (Fig. 4), with 32.05 weight $\%$ of Silicon, 30.91 weight $\%$ of Oxygen, 13.99 weight $\%$ of Aluminium, 11.76 weight $\%$ of Carbon, 5.54 weight $\%$ of Calcium, 4.74 weight $\%$ of Sodium and 1.0 weight $\%$ of Potassium (Table 2). Thus the wax crystals of $J$. auriculatum comprised mostly of five elements with Calcium, Oxygen and Carbon in sufficiently larger amounts, while the waxes of J. multiflorum had seven major components with Silicon and Oxygen in large amounts. Carbon and Calcium were seen in lower quantities here. Although Silicon, Sodium and Aluminium were additional components observed here, Magnesium present in J. auriculatum was not identified from the wax of J. multiflorum.

Table 1:- Elemental composition of epicuticular wax of Jasminum auriculatum

\begin{tabular}{|l|l|l|}
\hline Element & Weight \% & Atomic weight \% \\
\hline Carbon & 26.37 & 40.76 \\
\hline Oxygen & 35.52 & 41.22 \\
\hline Magnesium & 1.19 & 0.91 \\
\hline Potassium & 0.77 & 0.37 \\
\hline Calcium & 36.14 & 16.74 \\
\hline
\end{tabular}

Table 2:- Elemental composition of epicuticular wax of Jasminum multiflorum

\begin{tabular}{|l|l|l|}
\hline Element & Weight \% & Atomic weight \% \\
\hline Carbon & 11.76 & 19.82 \\
\hline Oxygen & 30.91 & 39.10 \\
\hline Sodium & 4.74 & 4.17 \\
\hline Aluminium & 13.99 & 10.50 \\
\hline Silicon & 32.05 & 23.10 \\
\hline Potassium & 1.00 & 0.52 \\
\hline Calcium & 5.54 & 2.80 \\
\hline
\end{tabular}

Intra-epidermal plant crystals are often considered to be Calcium Carbonate or Calcium Oxalate. Yashvanth et al. (2013) conducted SEM-EDX analysis of the elemental composition of various plant parts and crystals of Leucas aspera and reported over $54 \%$ of Oxygen and 38\% of Carbon from the adaxial surface of leaves. Calcium and Silica were noted in very small amounts. Higher content of elemental Oxygen was observed in the present study also, despite differences with regard to the presence and composition of other elements in the waxes of the two Jasminum species studied. Here Calcium and Silicon were observed in larger percentages. This variation in crystal composition needs to be further evaluated to assess whether they are species-specific and would be of aid in the systematic evaluation of the genus. 


\section{Conclusion:-}

Foliar epicuticular wax micromorphology and elemental composition shows much variation among the two species of Jasminum presently studied. This variation in wax morphology and composition needs to be explored further for assessing their potential use as additional markers in elucidating the systematic inter-relationships between the various members of the genus.

\section{Acknowledgements:-}

UGC-Delhi for financial support \& Principals, Sree Narayana Colleges, Kollam \& Chempazhanthy for facilities provided.
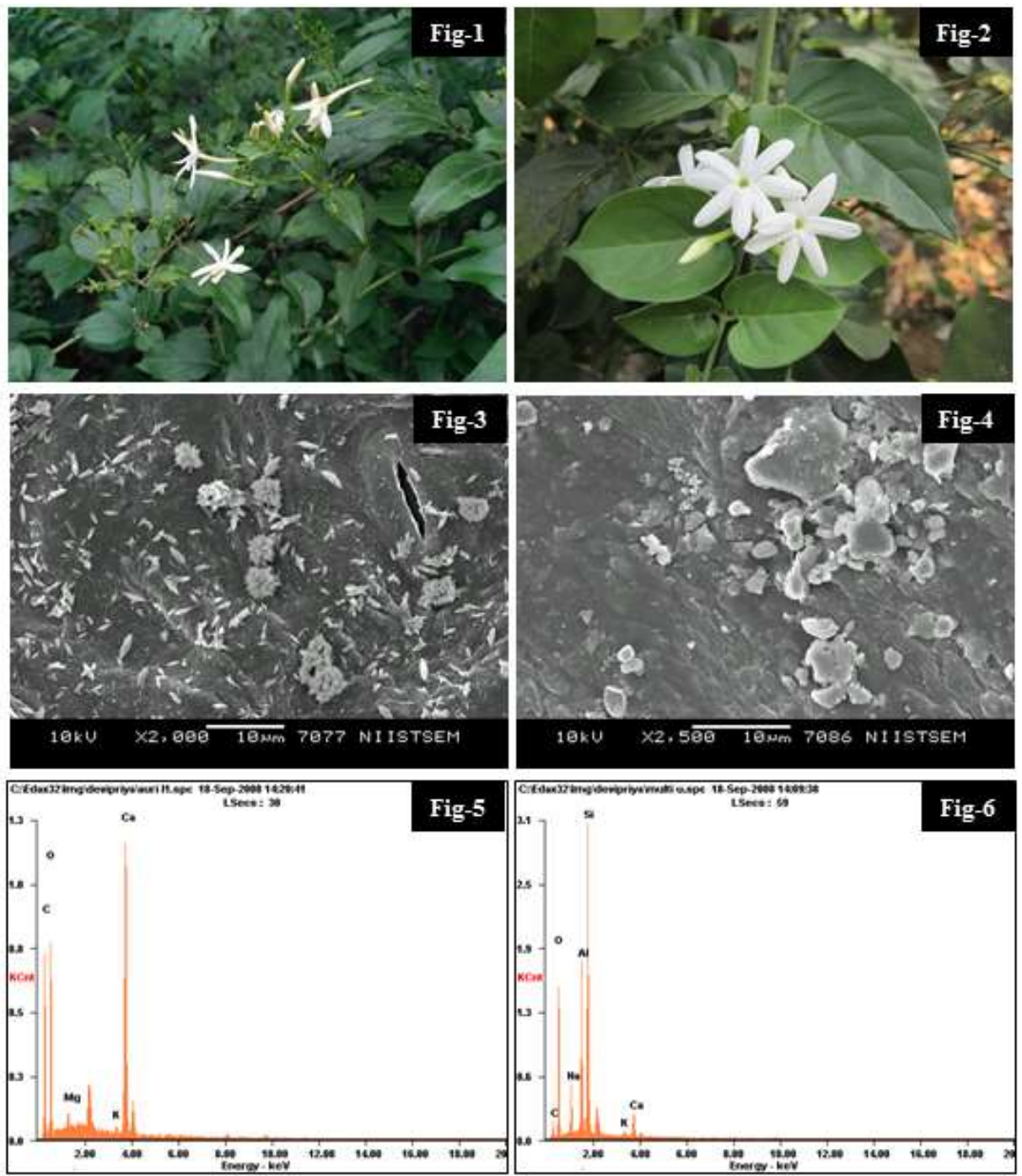

Fig. 1:-Habit of Jasminum auriculatum Vahl; Fig. 2: Habit of Jasminum multiflorum(Burm.f.) Andrews; Fig. 3: Lower epidermis of Jasminum auriculatum(Scanning Electron Micrograph, 2000x); Fig. 4: Upper epidermis of Jasminum multiflorum(Scanning Electron Micrograph,2500x); Fig. 5: SEM-EDX showing elemental composition of epicuticular wax in Jasminum auriculatum; Fig. 6: SEM-EDX showing elemental composition of epicuticular wax in Jasminum multiflorum 


\section{References:-}

1. Barthlott, W. (1990): Scanning electron microscopy of the epidermal surface of plants. In: Claugher D (eds) Scanning EM in taxonomy and functional morphology. Clarendon Press, Oxford. Vol. 41. pp. 69-94.

2. Barthlott, W. and Theisen, I. (1995): Epicuticular wax structure and classification of Ranunculiflorae. In: Jensen U, Kadareit JW (eds) Systematics and evolution of the Ranunculiflorae. Plant Syst. Evol. Suppl. 9. pp. 39-45.

3. Barthlott, W., Neinhuis, C., Jetter, R., Bourauel, T. and Riederer, M. (1996): Waterlily, poppy, or sycamore: on the systematic position of Nelumbo. Flora, 191: 169-174.

4. Behnke, H.D. and Barthlott, W. (1983): New evidence from the ultrastructural and micromorphological fields in angiosperm classification. Nordic J. Bot., 3: 43-66.

5. Chen, S., Diekmann, H., Janz, D. and Polle, A. (2014): Quantitative X-ray elemental imaging in plant materials at the subcellular level with Transmission electron microscope: applications and limitations. Materials, 7: 31603175 .

6. Dahlgren, R. and Bremer, K. (1985) Major clades of the angiosperms.Cladistics, 1: 349-368.

7. De Candolle, A.P. (1844): Prodromus Systematis Naturalis Regni Vegetabilis 8. Treuttel \& Wfirtz. Paris.

8. Green, P.S. (1969): Studies in the genus Jasminum L. IV. These so called new world species. Kew Bulletin, 23: 273-275.

9. Green, P.S. (2001): Studies in the genus Jasminum, XVII: Sections Trifoliolata and Primulina. Kew Bulletin, 56: 903-915.

10. Riederer, M. and Schreiber, L. (1995): Waxes - the transport barriers of plant cuticles. In: Hamilton RJ (eds) Waxes: Chemistry, Molecular Biology and Functions. The Oily Press, Dundee, pp-131-156.

11. Yashvanth, S., Sobha Rani, S. and Madhavendra, S.S. (2013): Microchemical (Elemental) analysis of Leucas aspera (Willd.) Link employing SEM-EDAX. Inter. J. Pharm. Sci. Drug Res., 5(1): 32-35. 